\title{
Biomechanical thrombosis: the dark side of force and dawn of mechano- medicine
}

\author{
Yunfeng Chen (D) , ${ }^{1}$ Lining Arnold Ju (D) ${ }^{2}$
}

To cite: Chen Y, Ju LA. Biomechanical thrombosis: the dark side of force and dawn of mechano-medicine. Stroke \& Vascular Neurology 2020;5: e000302. doi:10.1136/svn2019-000302

YC and LAJ contributed equally.

Received 12 November 2019 Accepted 14 November 2019 Published Online First 15 December 2019

\section{Check for updates}

(C) Author(s) (or their employer(s)) 2020. Re-use permitted under CC BY-NC. No commercial re-use. See rights and permissions. Published by BMJ.

${ }^{1}$ Molecular Medicine, Scripps Research Institute, La Jolla, California, USA

${ }^{2}$ School of Biomedical Engineering, Heart Research Institute and Charles Perkins Centre, The University of Sydney, Camperdown, New South Wales, Australia

Correspondence to Dr Yunfeng Chen; cheny@scripps.edu

Dr Lining Arnold Ju; arnold.ju@sydney.edu.au

\section{ABSTRACT}

Arterial thrombosis is in part contributed by excessive platelet aggregation, which can lead to blood clotting and subsequent heart attack and stroke. Platelets are sensitive to the haemodynamic environment. Rapid haemodynamcis and disturbed blood flow, which occur in vessels with growing thrombi and atherosclerotic plaques or is caused by medical device implantation and intervention, promotes platelet aggregation and thrombus formation. In such situations, conventional antiplatelet drugs often have suboptimal efficacy and a serious side effect of excessive bleeding. Investigating the mechanisms of platelet biomechanical activation provides insights distinct from the classic views of agonist-stimulated platelet thrombus formation. In this work, we review the recent discoveries underlying haemodynamic force-reinforced platelet binding and mechanosensing primarily mediated by three platelet receptors: glycoprotein Ib (GPIb), glycoprotein Ilb/llla (GPIlb/ IIla) and glycoprotein VI (GPVI), and their implications for development of antithrombotic 'mechano-medicine' .

\section{INTRODUCTION}

Thrombotic diseases, which include the acute coronary syndromes, ischaemic stroke and peripheral vascular disease, remain the leading causes of death and disability worldwide. ${ }^{12}$ Platelets play a central role in the pathogenesis of arterial thrombosis. However, despite intensive investigations over the last 40 years into the discovery and development of antiplatelet therapies, the impact of these therapies on the mortality rate remains disappointingly low: $<1$ in 6 patients taking antiplatelet therapies avoided a fatal thrombotic event. ${ }^{1}$ This situation is likely to worsen in the next few decades due to the rapidly growing incidence of obesity, diabetes and metabolic syndrome, which all enhance the resistance of arterial thrombosis to conventional antiplatelet drugs. ${ }^{3}$

The development of more effective antithrombotic approaches requires a better understanding of the molecular events underlying platelet hyperactivity and excessive thrombus growth. To date, most of the Food and Drug Administration (FDA) approved antithrombotic agents target agonist pathways of platelet activation, including the purinergic
P2Y ${ }_{12}$ receptor antagonists (clopidogrel, prasugrel, ticagrelor), inhibitors of thromboxane A2 (TxA2) generation (aspirin, triflusal) or protease-activated receptor 1 (PAR1) antagonists (vorapaxar). ${ }^{1}$ Increasing the dose of these agents, especially aspirin and clopidogrel, has been employed to dampen the platelet thrombotic functions. However, this also increases the risk of excessive bleeding. ${ }^{4}$ It has long been recognized that arterial thrombosis is regulated by biomechanical factors, particularly pathological shear stress and flow disturbance associated with vessel stenosis induced by atherosclerotic plaques or medical device implants. ${ }^{15}$ These variations in blood haemodynamics can be sensed by platelets, upregulating platelet adhesive functions and inducing platelet activation via a process called 'mechanosensing' ${ }^{67}$ Recent technology advancements in microfluidics, molecular imaging and live-cell dynamic force spectroscopy enabled the investigation of platelet mechanosensing at single-cellular and single-molecular levels. These studies looked into how platelets sense and react to the extracellular haemodynamic forces, and defined the mechanosensing functions of receptors GPIb, GPIIb/IIIa and possibly GPVI, in mediating shear-dependent platelet adhesion, ${ }^{8-10}$ spreading ${ }^{11}$ and aggregation. ${ }^{512}$ These insights provided new targets for the next-generation antithrombotic strategies.

Biomechanical versus biochemical activation in platelet adhesion and aggregation

Thrombosis requires platelet adhesion, but also heavily relies on platelet aggregation to form occlusive thrombi. Platelet adhesion and aggregation are both complex processes that involve the binding between multiple receptor-ligand pairs. ${ }^{13}$ In veins where shear rates are low $\left(300-800 \mathrm{~s}^{-1}\right)$, initial platelet adhesion is mainly mediated by GPVI interaction with collagen and GPIIb/IIIa with fibrinogen in subendothelium (figure 1). The subsequent platelet aggregation is primarily mediated by the GPIIb/IIIa binding to divalent or 


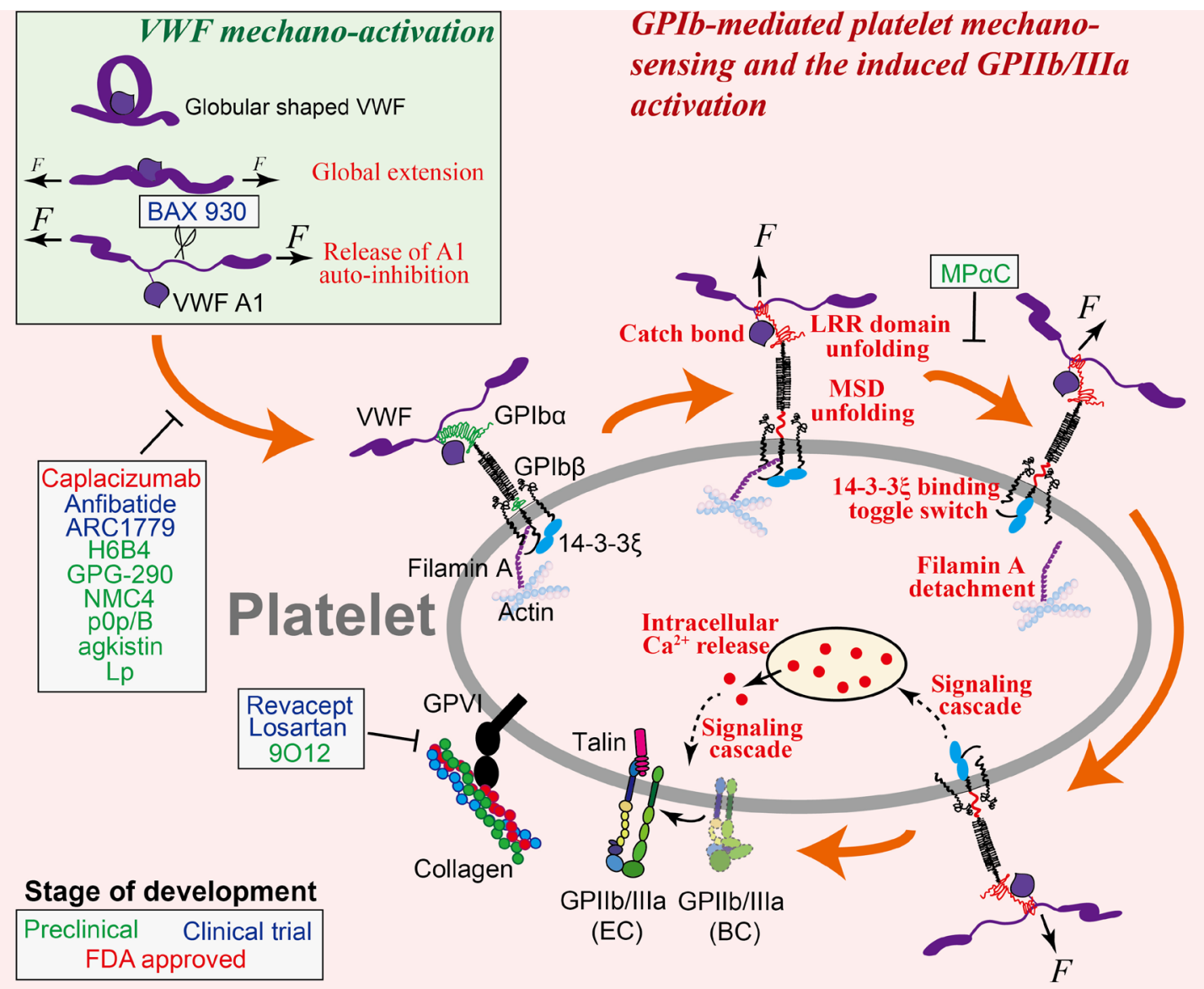

Figure 1 Illustration of VWF mechanoactivation (inset) and the step-by-step process of GPIb-mediated platelet mechanosensing. VWF is activated by shear flow in two steps: it is first globally elongated from a globular to an extended conformation, followed by the relief of its A1 domain autoinhibition that enables binding to platelet GPIb $\alpha$. Once VWF is bound to a platelet, force from the shear flow transmits from VWF to GPIb $\alpha$ and triggers a series of GPIb $\alpha$ conformational changes and allosteric effects. These events would result in the reinforcement of VWF-GPIb interaction as well as the initiation of a mechanosignaling pathway that eventually leads to intracellular calcium release and GPIlb/llla activation. Note: platelet GPVI and its interaction with collagen are also depicted in this graph. Agents and drugs that have the potential to inhibit arterial thrombosis by targeting GPIb-mediated or GPVI-mediated platelet binding and mechanosensing, and their respective targets, are indicated, corresponding to table 1.

multivalent ligands for crosslinking. These include von Willebrand factor (VWF), which adopts a structure of a colloid concatemer, ${ }^{14-16}$ and fibrinogen, which has a total of six motifs to interact with GPIIb/IIIa. ${ }^{17-19}$ In addition, fibronectins can attach to two ends of a fibrinogen molecule and crosslink platelet GPIIb/IIIa as well. ${ }^{20-22}$ In arteries and arterioles where shear rate is relatively high $\left(>800 \mathrm{~s}^{-1}\right)$, both GPIb and GPIIb/IIIa serve as the primary mediators of platelet adhesion ${ }^{23} 24$ and aggregation. ${ }^{525} \mathrm{In}$ particular, at pathologically high shear rates $\left(>5000 \mathrm{~s}^{-1}\right)$ that occur in arteries with severe stenosis, the GPIb-VWF interaction alone can achieve large-scale platelet aggregation independent of integrin and platelet activation. ${ }^{26}$

Platelet adhesion and aggregation are heavily dependent on platelet activation, mainly due to the fact that platelet activation primes GPIIb/IIIa to achieve stronger binding capacity. ${ }^{13}{ }^{23}$ Additionally, platelet activation also results in platelet spreading and granule release to allow ligand deposition as well as surface expression of extra receptors for binding. ${ }^{1127-29}$ Platelets can be activated by soluble agonists via $\mathrm{G}$ protein-coupled receptor (GPCR) signaling pathways. For instance, ADP (by binding to $\mathrm{P}_{2} \mathrm{Y}_{1}$ and $\mathrm{P}_{2} \mathrm{Y}_{12}$ ), ${ }^{30}{ }^{31}$ thromboxane A2 (by binding to thromboxane A2 receptor) ${ }^{32}$ and thrombin (by binding to PAR1 and PAR4) ${ }^{33}$ can induce GPIIb/IIIa inside-out activation at various levels to trigger cytoskeletal remodelling, granule release, degranulation and cell death, ${ }^{134} 35$ while the inhibition of these interactions or their subsequent signaling pathways has been employed to develop antithrombotic drugs like clopidogrel ${ }^{36}$ aspirin, ${ }^{37}$ warfarin ${ }^{38}$ and heparin. ${ }^{39}$ In parallel, platelets can be biomechanically activated via binding to its extracellular ligands under shear. ${ }^{7}$ In this process, force pulling on a platelet receptor triggers 'mechanosignals' across the membrane and results in intracellular signal transduction. ${ }^{6}$ Platelet GPIb and GPIIb/IIIa together form an important mechanosensing axis. ${ }^{40}$ GPIb initiates platelet mechanosignaling by binding to immobilised VWF under force, which is followed by the mechanosignaling of GPIIb/IIIa while binding to its own ligands, eventually allowing rapid 
shear-dependent thrombus formation. ${ }^{12}$ Importantly, the intensity and timing of GPIb mechanosignaling is quantitatively correlated with the level of subsequent GPIIb/IIIa activation in both affinity and avidity, ${ }^{12}$ which highlights the role of GPIb as a mechanosensor in shear-dependent platelet thrombus formation.

\section{The role of VWF-GPIb axis in platelet binding and mechanosensing}

VWF contains binding sites for both platelet GPIb and GPIIb/IIIa, respectively, in its A1 and C4 domains. ${ }^{41}$ The VWF molecule itself is mechanosensitive, which undergoes conformational activation under shear force. The inactive form of VWF in plasma adopts a globular, irregularly coiled shape, with its functional epitopes buried. In particular, its A1 domain is autoinhibited by the adjacent N-terminal D'D3 domain ${ }^{42}$ and C-terminal A2 domain, ${ }^{43} 44$ which prevents the accessibility of VWF-A1 to GPIb. Under high-shear laminar flow or high-shear gradient disturbed flow, VWF is mechanically extended by shear force to expose its platelet-binding epitopes. ${ }^{41} 45$ Further exertion of force on the extended VWF unmasks its A1 domain and relieves the autoinhibition of its GPIbbinding site, thereby allowing platelet GPIb binding ${ }^{46-49}$ (figure 1). Besides, shear can facilitate the self-association of VWF into fibres, which further enhances platelet adhesion and activation. ${ }^{50} 51$

The VWF A1 domain autoinhibition was suggested to be controlled by the C1669-C1670 disulfide bond plug in the A2 domain. ${ }^{52}$ Three different redox forms of this disulfide plug were discovered to exist in circulating human VWF: reduced, glutathionylated and oxidized. The oxidized form has high affinity for platelet GPIb, whereas the reduced and glutathionylated forms have low affinity. Clinically, most of heart failure patients who have received extracorporeal membrane oxygenation (ECMO) support have markedly more oxidized VWF in the circulation, ${ }^{53}$ which seems to result from the dysregulated blood shear associated with the device but not the disease or therapy variations. ${ }^{52}$ This result explains the thrombotic complications associated with ECMO device, and suggests that reducing this disulfide plug might provide protection to patients against thrombosis.

The VWF-GPIb interaction features fast bond association and dissociation, which plays a primary role in platelet recruitment from rapid blood circulation. ${ }^{54-56}$ A counterintuitive phenomenon was discovered in this interaction: increasing the shear rate would enhance, rather than reduce, platelet adhesion onto a VWFcoated surface. ${ }^{2355} 57$ Using single-cell force spectroscopies, this phenomenon was explained by a 'catch bond' behaviour ${ }^{55}$ and a force-induced unfolding of the GPIb leucine rich repeat (LRR) domain, ${ }^{58}$ in both of which mechanical force reinforces VWF-GPIb bond strength (figure 1). Taken together, the mechanosensitivity of VWF and the force reinforcement of VWF-GPIb interaction work cooperatively to allow platelets to resist highshear forces in the arteries while being recruited to the vascular injury site. However, they also promote thrombus development under pathological shear conditions ${ }^{59}$ : as shear rate increases to $5000 \mathrm{~s}^{-1}$, the VWF-GPIb interaction starts to mediate large platelet aggregate formation $\left(>100 \mu \mathrm{m}^{2}\right)$, and this effect becomes more pronounced as the shear rate increases to $10000 \mathrm{~s}^{-1}$ and above. ${ }^{26}$

VWF-GPIb interaction not only mediates platelet binding but also triggers the outside-in mechanosignals of platelets independent of other receptors, leading to intraplatelet calcium flux ${ }^{60}$ and GPIIb/IIIa activation. ${ }^{8} 10$ Inhibition of the GPIb-triggered $\mathrm{Ca}^{2+}$ prevents platelet firm adhesion, suggesting that $\mathrm{Ca}^{2+}$ is an obligatory signaling molecule on the pathway to GPIIb/IIIa activation. ${ }^{896162}$ Although how the transmission of the mechanical signal across the membrane and its transduction into cytoplasmic chemical signals are fulfilled remains elusive, ajuxtamembrane mechanosensitive domain (MSD) in the GPIb $\alpha$ subunit was found to correlate with intraplatelet $\mathrm{Ca}^{2+}$ triggering (figure 1): force-induced MSD unfolding is well correlated with an $\alpha$-type $\mathrm{Ca}^{2+}$ signal $^{89}$ and the subsequent GPIIb/IIIa intermediate activation, whereas failing to unfold MSD will most likely result in $\beta$-type or null-type $\mathrm{Ca}^{2+}$ signals and limit GPIIb/IIIa activation. ${ }^{60} 63$ Intracellularly, a scaffold protein that binds to

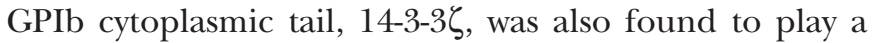
pivotal role in GPIb mechanosignaling (figure 1), as the inhibition of 14-3-3ל-GPIb association strongly inhibited GPIb-triggered $\mathrm{Ca}^{2+}$ flux and subsequent GPIIb/IIIa activation. ${ }^{6064}$ Filamin $\mathrm{A}$, another cytoplasmic protein that links GPIb with the cytoskeleton, was also speculated to participate in GPIb mechanosignaling ${ }^{65}$ (figure 1). At the downstream of this signal transduction pathway, the phosphorylation of kinases (including Akt and focal adhesion kinase (FAK)) is required, which involves the Src family kinases $^{66}$ as well as the activation of several signaling pathways including the phosphoinositide 3-kinase (PI3K)-Akt and cGMP-dependent protein kinase pathway, mitogenactivated protein kinase (ERK1/2 and p38) pathway and LIM kinase 1 pathway. ${ }^{67}$

\section{Targeting VWF-GPIb axis as a novel antithrombotic strategy} Many works have explored the potential of inhibiting VWF-GPIb interaction to reduce arterial thrombosis. ${ }^{68}$ For instance, Chen et al discovered a 'hot spot' residue R1326 on murine VWF-A1. ${ }^{69}$ Mutating this residue to histidine weakens both the association and endurance of VWF-GPIb binding, thereby diminishing thrombus formation in arterioles in a laser-injury thrombosis model. ${ }^{70}$ The autoinhibitory effect of the N-terminal sequence Q1238-E1260 of VWF-A1 on its own binding to platelet GPIb inspires another potential antithrombotic approach: the soluble polypeptide Lp of the same sequence was shown to inhibit platelet binding to $\mathrm{VWF}$ under shear. ${ }^{57}$ A humanized anti-VWF-A1 blocking nanobody named ALX-0081 (caplacizumab) inhibited acute thrombosis without compromising haemostasis in baboons, ${ }^{71}$ and induced the reperfusion of a thrombusoccluded cerebral artery without provoking cerebral 
bleeding in guinea pigs. ${ }^{72}$ Besides, an inhibitory monoclonal antibody against VWF-A1, NMC4 ${ }^{73}$ a recombinant mimetics of human GPIb $\alpha$, GPG-290 ${ }^{74}$ and an anti-VWF aptamer, ARC1779, ${ }^{75}$ were also found to inhibit thrombosis (table 1; figure 1). Similarly, the inhibition of GPIb binding by monoclonal antibodies $\mathrm{H} 6 \mathrm{~B} 4^{76}$ and $\mathrm{p} 0 \mathrm{p} / \mathrm{B},{ }^{77}$ or by chemicals purified from snake venom like agkistin ${ }^{78}$ and anfibatide, ${ }^{79}$ were found to reduce platelet aggregation and thrombus formation under arterial shear conditions (table 1; figure 1). The anti-GPIb blockade has displayed a strong protective effect in the mouse stroke models without inducing significant intracranial bleeding. ${ }^{7780}$ Notably, unpublished phase IIa human clinical trials have shown the promise of anfibatide as a novel antiplatelet agent without significantly affecting haemostasis in patients with non-ST segment elevation myocardial infarction (MI) ${ }^{81}$ Additionally, anfibatide was also shown as a promising candidate to treat ischaemic stroke and spontaneous or bacterial shigatoxin-induced acquired thrombotic thrombocytopenic purpura (TTP) in experimental animal models. ${ }^{82} 83$

Nonetheless, due to the indispensable role of VWFGPIb interaction in initiating platelet haemostatic functions, inhibiting this axis can easily trigger a strong side effect of excessive bleeding. Historically, this has caused the failure of several clinical trials. ${ }^{4}{ }^{84}$ For instance, although a phase II trial demonstrated that ARC1779 reduced cerebral thromboembolism after carotid endarterectomy, two-thirds of patients receiving ARC1779 experienced haemorrhagic complications. ${ }^{85}$ As another example, caplacizumab was trialled in combination with aspirin, clopidogrel and heparin in high-risk patients with acute MI undergoing percutaneous coronary intervention (PCI) ${ }^{86}$ However, its development was discontinued in 2011 because of a severe bleeding profile. ${ }^{84}$ Instead, it received FDA approval following phase III HERCULES trials for the treatment of acute episode of acquired TTP in adult patients in combination with plasma exchange and immunosuppressive therapy. ${ }^{87}$ We argue that similar outcome may hold true for other drug candidates that generally inhibit VWF-GPIb interaction, which deserve careful consideration and further investigation.

On a separate note, considering the distinct haemodynamic conditions associated with arterial thrombosis and haemostasis, a potential strategy to selectively inhibit arterial thrombosis without compromising haemostasis is to target the biomechanical activation of $\mathrm{VWF}$ and/or the biomechanical reinforcement of VWF-GPIb interaction. For instance, inhibiting the LRR domain unfolding of GPIb $\alpha$ may serve to suppress VWF-GPIb interaction under high forces, ${ }^{58}$ thereby hampering thrombosis in stenosed arteries where shear rate is pathologically high. As another example, shear force unfolds the A2 domain of ultra-large VWF to allow its cleavage by ADAMTS13 into normal sizes. ${ }^{88}$ It was found that under pathologically high-shear flow, shear force becomes sufficiently large to trigger cleavage of normal-sized VWF by ADAMTS13 in a growing thrombus, thereby inhibiting thrombosis. ${ }^{88} 89$
This makes recombinant ADAMTS13 (BAX 930) a promising antithrombotic agent ${ }^{90}$ (table 1; figure 1 ): in preclinical tests, infusing recombinant ADAMTS13 before reperfusion significantly reduced the infarct volume and other stroke effects. ${ }^{91}$ Moreover, the mechanoredox regulation of VWF reactivity suggests that using antioxidative agents or more specific disulfide isomerases to reverse plasma VWF from oxidized to its reduced form can reduce platelet binding and thereby suppress thrombosis. ${ }^{52}$

Since GPIb mechanosignaling leads to GPIIb/IIIa activation, ${ }^{12}$ the GPIb signaling pathway serves as another target to inhibit thrombosis. However, blocking housekeeping cytoplasmic adaptors and signaling kinases would most likely affects physiological functions of other cell types. Considering this, targeting certain steps of the GPIb mechanosignaling process seems more promising due to higher specificity. Previous works have identified that a small peptide, MP $\alpha \mathrm{C}$, which inhibits the association of 14-3-3 $\zeta$ with GPIb, suppresses mouse arterial thrombosis with minor consequences of bleeding ${ }^{92}{ }^{93}$ (table 1 ; figure 1). Inhibiting the unfolding of MSD should also suppress the mechanosignaling of GPIb. The current development of bispecific antibody technology ${ }^{94}$ provides a possible approach to achieve this: by making a bispecific antibody with two antigen binding fragments respectively targeting the two ends of MSD, it can potentially constrain MSD in its folded conformation even under force pulling.

\section{The role of GPIIb/IIla in platelet binding and mechanosensing} A good amount of works have substantially characterized GPIIb/IIIa as a platelet receptor in structure, ${ }^{95-100}$ binding activity ${ }^{101-103}$ and signaling. ${ }^{8911} 62104105$ GPIIb/IIIa regulates its ligand-binding affinity with conformational changes. ${ }^{106-108}$ Inactive GPIIb/IIIa adopts a bent conformation (B) with closed headpiece (C) (or called hybrid domain swung-in); its ligand binding site is inactive and barely binds any ligand. On activation, the GPIIb/IIIa extends its ectodomain to achieve an extended-closed (EC) conformation, followed by headpiece opening to reach extended-open (EO) ${ }^{95} 98^{109-112}$ (figure 2A). The EO conformation of GPIIb/IIIa is extensively correlated with active ligand binding, ${ }^{98} 113$ whereas the EC conformation was recently found to be associated with an intermediate affinity state. ${ }^{12}$

GPIIb/IIIa plays critical roles in platelet adhesion, activation and aggregation, which altogether define it as the primary mediator of both thrombosis and haemostasis. ${ }^{114-117}$ As first observed in mouse stenosed blood vessels and in varied arterial injury models, GPIIb/IIIa can mediate platelet aggregation in a biomechanical pathway, ${ }^{25}$ where the platelets mainly remain discoid. ${ }^{5}$ In the biomechanical platelet aggregation, the interaction between GPIb and VWF initiates platelet mechanosensing and results in the EC conformation, intermediate affinity activation of GPIIb/IIIa. ${ }^{891260}$ Once upregulated to this intermediate state, GPIIb/IIIa starts to receive mechanosignals to undergo outside-in signaling, which leads to its own activation to the high affinity, EO state (figure 2A) 


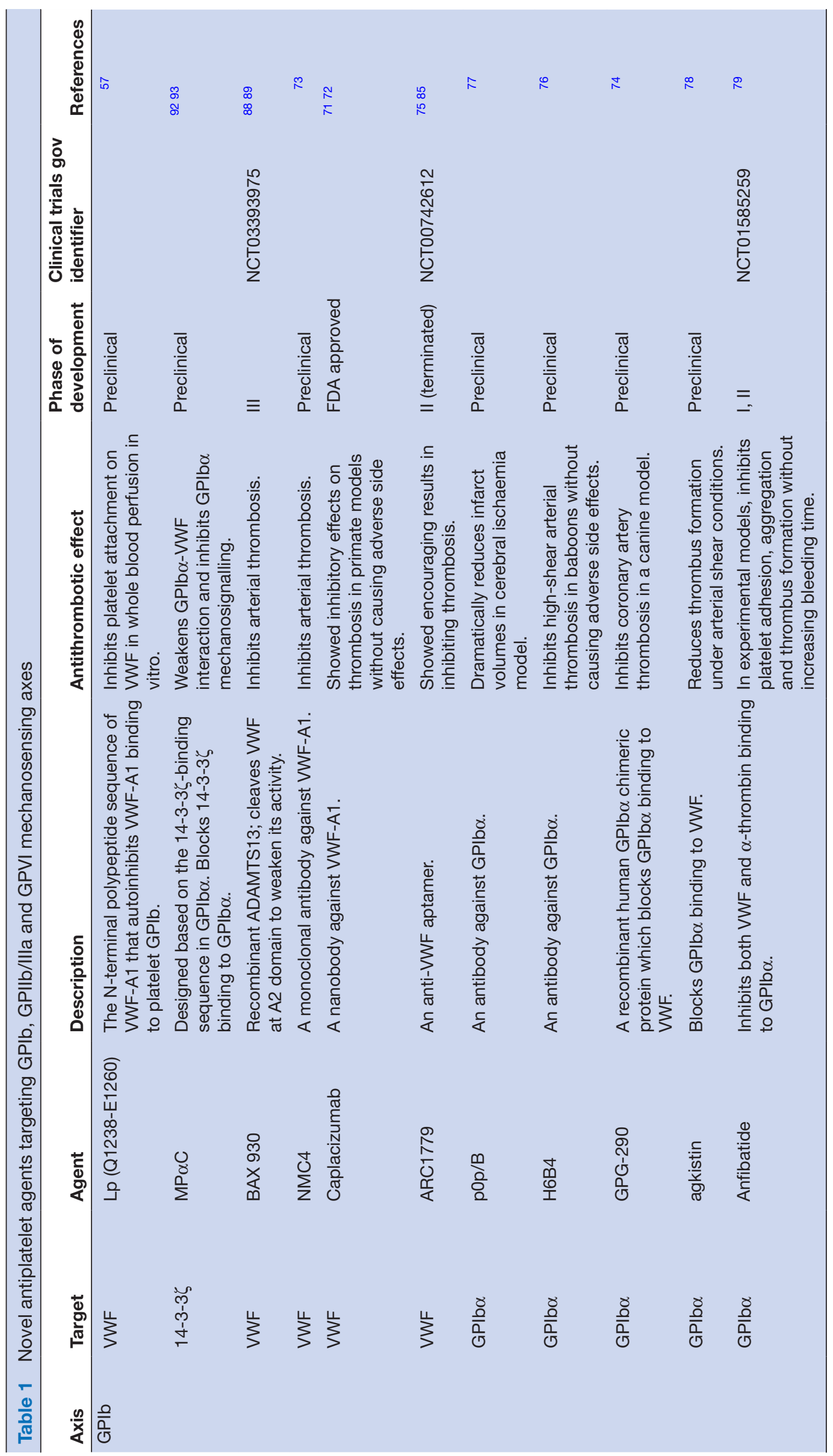




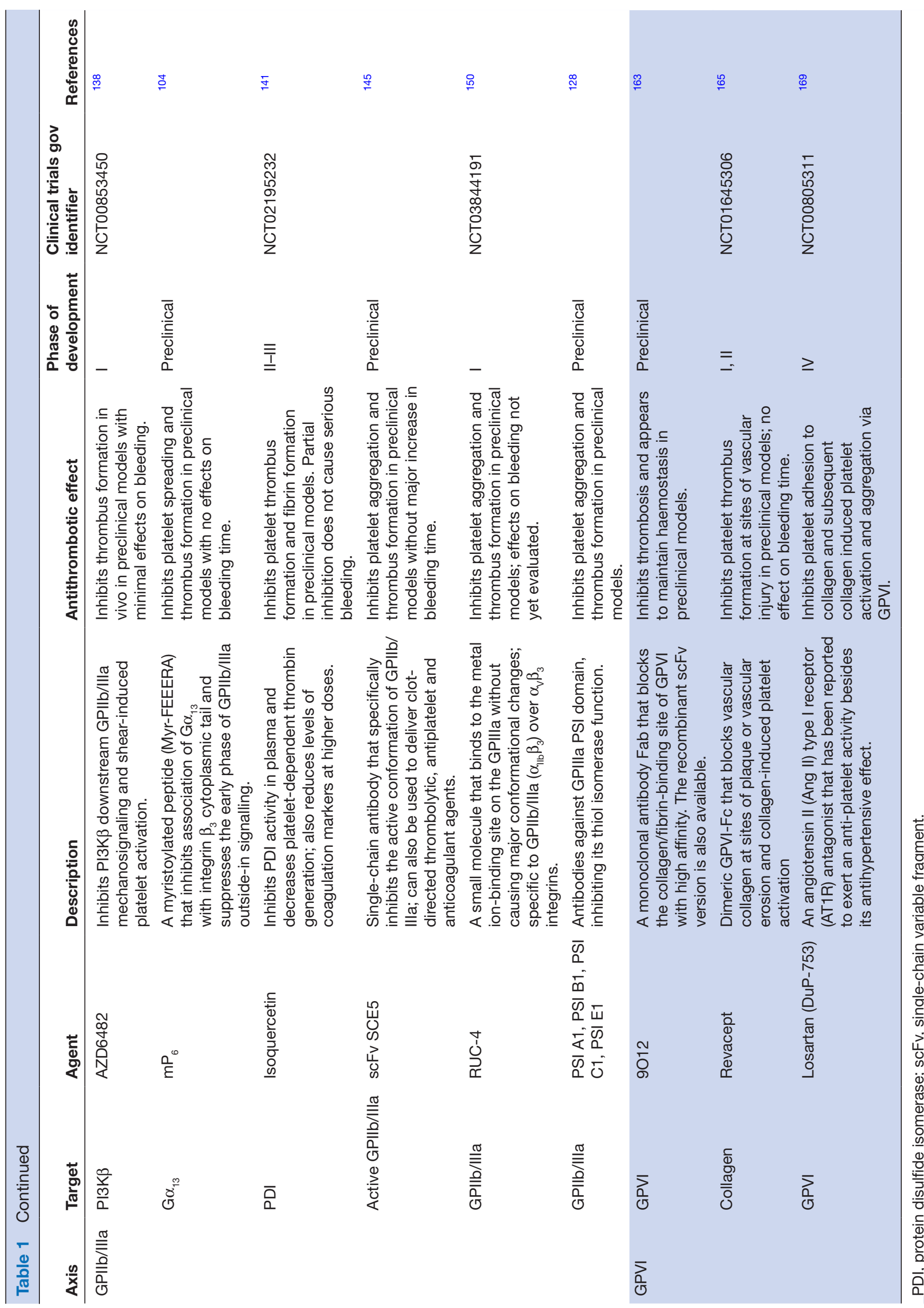



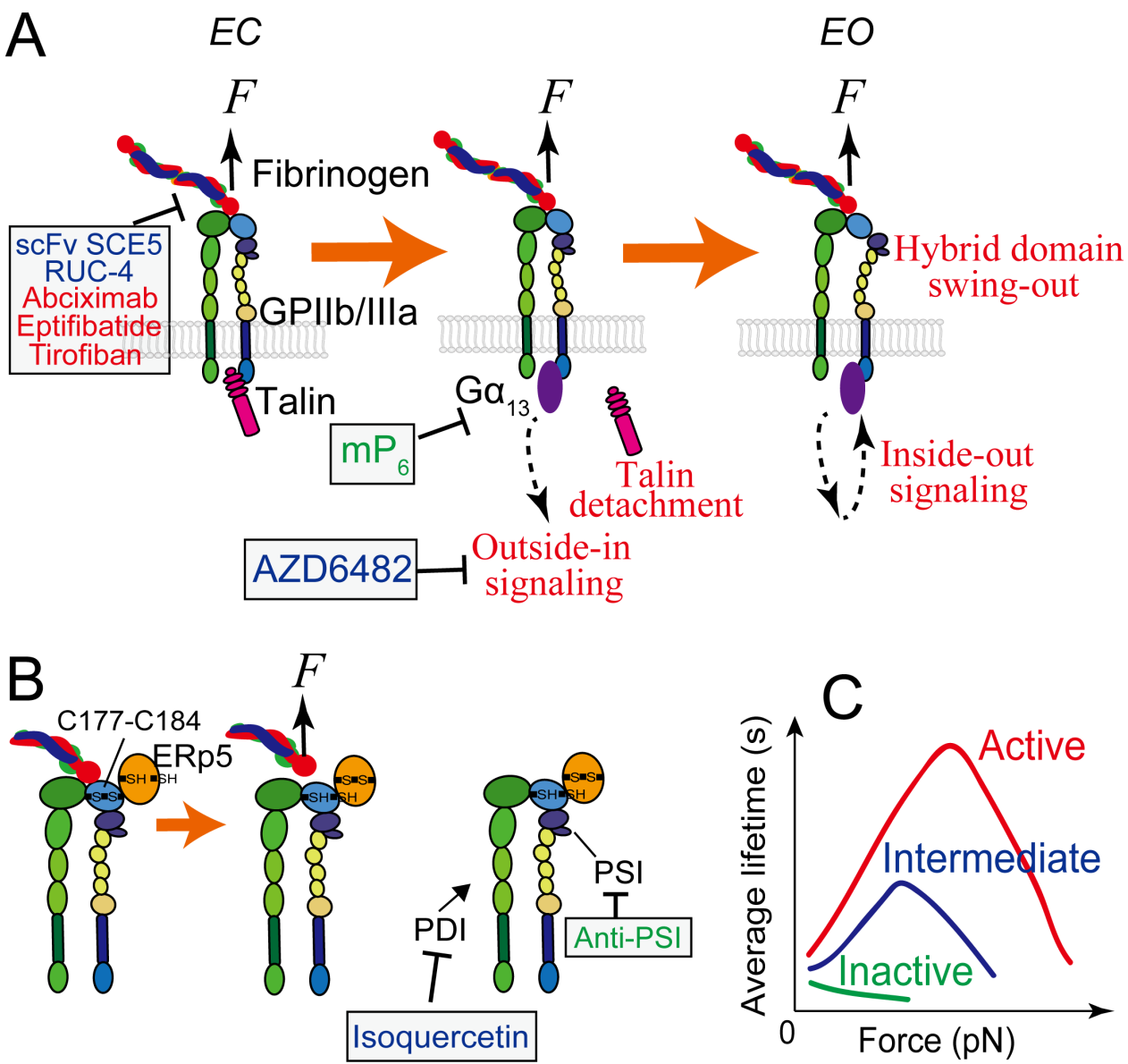

Figure 2 GPIlb/IIla mediated platelet mechanosensing. (A) The extended-close (EC) GPIlb/Illa receives mechanosignals from its bound ligand and mediates outside-in signaling, which can subsequently upregulate GPIIb/IIla themselves towards the active state with an extended-open (EO) conformation. During the process, the adaptor protein talin that is originally associated with the cytoplasmic tail of GPIIla will detach and be replaced by a $\mathrm{G} \alpha_{13}$ molecule, which will be ensued by a second wave of talin attachment to in turn replace $\mathrm{G \alpha}_{13}$ (not depicted here). (B) Redox regulation of GPIIb/Illa binding via ERp5, PSI and PDI. Force pulling on the GPIIb/IIla headpiece via a bound Arg-Gly-Asp (RGD)-bearing ligand can facilitate ERp5 to reduce the C177-C184 disulfide bond in the $\beta$ I domain, which in turn accelerates ligand dissociation from GPIIb/Illa. PSI domain has endogenous thiol isomerase function, which reinforces GPIlb/Illa binding. Extracellular PDI can also induce thiol-disulfide exchange in GPIlb/Illa and enhances its binding capacity. (C) In the resting bent-closed (BC) state, GPIIb/Illa binding to fibronectin manifests a slip bond (a small catch bond if against fibrinogen). Once upregulated to the intermediate extended-closed (EC) state, GPIIb/IIla binding to both ligands will adopt a strong catch bond, which will become even stronger when the integrin is further activated to the EO state. Agents and drugs (green: preclinical phase; blue: undergoing clinical trials; red: FDA approved) that have the potential to inhibit arterial thrombosis by targeting GPIlb/IIla mechanosensing, and their respective targets, are indicated, corresponding to table 1. 'Anti-PSI' represents antibodies PSI A1, PSI B1, PSI C1 and PSI E1. ERp5, endoplasmic reticulum 5; PDI, protein disulfide isomerase.

as well as platelet spreading, extracellular $\mathrm{Ca}^{2+}$ influx and granule secretion. 81227104118119 Remarkably, the above process does not require the external supplement of soluble agonists. Therefore, the activation of GPIIb/IIIa via this pathway was named 'mechanical affinity maturation'. ${ }^{12}$ Likely serving as a self-inhibitory mechanism to avoid overly activation of platelets, only the intermediate state, but not inactive state GPIIb/IIIa can undergo outside-in mechanosignaling. ${ }^{12}$ Importantly, the biomechanically driven activation (via sequential GPIb and GPIIb/IIIa mechanosignaling) and agonist-stimulated activation (via stimulation of soluble agonists) of GPIIb/ IIIa are essentially distinctive and probably via differential signaling pathways. $^{12}$
Mechanoredox coupling has been unravelled as a new mechanism by which GPIIb/IIIa biomechanically regulates platelet thrombosis. ${ }^{120-122}$ Thiol isomerases, including protein disulfide isomerase (PDI), ${ }^{123} 124$ endoplasmic reticulum 5 (ERp5) ${ }^{121}{ }^{125}$ and ERp57, ${ }^{126} 127$ are enzymes which regulate the function of platelets by reducing or oxidising disulfide bonds of their cell surface proteins, such as GPIIb/IIIa. Importantly, the regulation of these thiol isomerases can either strengthen or weaken GPIIb/IIIa binding. For example, the PSI domain of GPIIb/IIIa contains an endogenous thiol isomerase function, the inhibition of which suppressed platelet aggregation. ${ }^{128}$ On the other hand, another thiol isomerase ERp5 is secreted by activated platelets and binds to GPIIIa. ${ }^{121} 129$ 
Via reducing the $\beta$ I domain C177-C184 disulfide bond nearby the fibrinogen binding pocket of GPIIb/IIIa, ERp5 results in the premature release of fibrinogen. ${ }^{125}$ Importantly, Passam et alidentified this process to be force sensitive: RGD-ligand binding to the integrin and shear force can facilitate ERp5 to reduce the disulfide bond, thereby accelerating fibrinogen dissociation ${ }^{125}$ (figure 2B). This intriguing finding provides a new concept on how platelets harness force to balance haemostatic versus thrombotic functions from a redox perspective.

\section{Targeting GPIIb/IIla as a novel antithrombotic strategy} Just like GPIb, antagonists that directly block GPIIb/ IIIa extracellular binding have been developed for antithrombotic use. ${ }^{81} 130$ Among them, abciximab, eptifibatide and tirofiban are approved by FDA for acute cardiac ischaemic events. However, these antagonists would compromise haemostasis and induce profound thrombocytopenia with mechanisms incompletely understood. ${ }^{117} 131$ Clinicians have to heavily rely on the fine tuning of dosage to prevent these side effects from being life-threatening, which often fails. ${ }^{132}$ As a result, these GPIIb/IIIa inhibitors seem to be restricted to particular high-risk subgroups, such as MI patients undergoing PCI without pretreatment with a $\mathrm{P}_{2}{ }_{12}$ antagonist. ${ }^{133}{ }^{134}$ In the case of acute/moderate ischaemic stroke, their use is not recommended until multicentre analyses of endovascular stroke therapy necessitating adjunctive GPIIb/IIIa inhibitions are conducted. ${ }^{135}$

For the last decades, breakthroughs from basic research suggest new antithrombotic therapeutic targets underlying the early phases of GPIIb/IIIa intracellular signaling pathway. ${ }^{92} 104128136137$ For instance, selectively targeting GPIIb/IIIa downstream signaling molecules PI3K $\beta^{138}$ and $\mathrm{G \alpha}_{13}{ }^{104}$ was shown to inhibit arterial thrombosis without affecting haemostasis under certain doses (table 1; figure 2A). The PI3K $\beta$ inhibitor AZD6482, which suppresses GPIIb/IIIa mechanosignaling in particular, has completed preclinical and phase I clinical trials, and was demonstrated in multiple species including mice, rats, rabbits, dogs and humans for its good tolerance without prolonging skin bleeding time, even when administered at high doses. AZD6482 also demonstrated high efficiency in reducing the disturbed flow enhanced thrombotic response in a diabetic mouse model, which displayed resistance to co-administered aspirin and clopidogrel, ${ }^{139}$ suggesting that targeting platelet mechanosensing pathways provides a potentially more effective antithrombotic approach for patients with diabetes. On the other hand, inhibiting the interaction between GPIIb/IIIa and $\mathrm{G \alpha}_{13}$ with a myristoylated peptide ExE peptide motif $\left(\mathrm{mP}_{6}\right)$ selectively inhibits GPIIb/IIIa mediated platelet spreading but not agonist induced inside-out signaling or fibrinogen ligation ${ }^{104}$ (figure 2A). This peptide was shown to suppress occlusive arterial thrombosis without affecting bleeding. To explain this, our single-platelet analyses suggested that $\mathrm{G \alpha}_{13}$ binding is needed for the active EO state activation of GPIIb/IIIa, but not for the intermediate EC state activation ${ }^{12}$ (unpublished data). As such, preventing GPIIb/IIIa from the EC-EO transition might be a promising strategy to differentiate occlusive thrombosis from haemostasis.

The regulation of thiol isomerases was also suggested for antithrombotic application. For instance, inhibiting the thiol isomerase function of GPIIb/IIIa PSI domain by anti-PSI antibodies was demonstrated to inhibit murine thrombus formation without significantly affecting bleeding ${ }^{128}$ (figure 2B; table 1). Furthermore, inhibitors of PDI have been identified by high-throughput screening of 350000 compounds. ${ }^{122} 140$ Isoquercetin, a first-generation flavonoid anti-PDI drug derived from this screening, demonstrated good efficacy for reducing venous thrombosis in cancer patients in a phase II clinical trial $^{141}$ (figure 2B; table 1). These exciting results corroborate the rationale of targeting disulfide redox states of GPIIb/IIIa via thiol isomerase inhibitors. Importantly, patients with diabetes and metabolic syndrome have increased thiol isomerase activity in their blood, ${ }^{142} 143$ which raises the possibility of applying these inhibitors to these patients in the future.

Another promising antithrombotic strategy is to inhibit, but not eliminate, the ligand-binding capacity of GPIIb/IIIa. Catch bond mechanism was demonstrated to reinforce the ligand binding of activated GPIIb/IIIa ${ }^{12}$; in particular, compared with the EC intermediate state, the lifetime of EO GPIIb/IIIa is not only globally prolonged under all forces but also stretches its 'catch' regime with a wider force range ${ }^{12}$ (figure 2C). Such conformationspecific binding attributes of GPIIb/IIIa leads to steady development of thrombi even under pathologically shear rates in stenosed arteries. ${ }^{5}$ Taking advantage of this, a potential antithrombotic approach could be to downregulate the catch bond behaviour of activated GPIIb/IIIa at large forces. As a proof-of-concept, we demonstrated that a variant $(\mathrm{R} 77 \mathrm{H})$ in another integrin, $\alpha_{\mathrm{M}} \beta_{2}$, suppresses the integrin catch bond at $5-12 \mathrm{pN}$, but causes no effect to the bond lifetime at lower forces $(<5 \mathrm{pN}) .{ }^{144}$ Noting that R77 is located in the $\beta$-propeller domain distal to the ligand-binding site, this discovery highlights an allosteric effect in integrin binding regulation by integrin $\alpha$-subunit, which may also be applied to platelet GPIIb/ IIIa. The conformation-specific targeting of GPIIb/ IIIa represents another promising approach to partially inhibit GPIIb/IIIa. ${ }^{145}$ The selective targeting of the active EO conformation of GPIIb/IIIa should inhibit the propagation and stabilisation of thrombi, but not the formation of an initial haemostatic platelet plug on vascular injury-a process that relies on GPIIb/IIIa being in the low-activating BC/EC state. ${ }^{412}{ }^{146}$ Indeed, this concept has been proven in principle where a single-chain variable fragment $(\mathrm{scFv})$ SCE5 directed against the active conformation of GPIIb/IIIa markedly inhibited thrombosis on both human and mouse platelets (figure 2A), ${ }^{145}$ but did not prolong bleeding time in mouse models. ${ }^{145}$ Moreover, conformation-specific scFvs have been used to deliver targeted antithrombotic agents such as the 
ADP-hydrolysing enzyme CD39, ${ }^{147}$ the potent factor Xa inhibitor tick anticoagulant peptide ${ }^{148}$ and the fibrinolytic agent urokinase ${ }^{149}$ to the selective sites of developing clots, which all displayed potent antithrombotic effects in preclinical models without affecting haemostasis. ${ }^{4}$

One caveat of GPIIb/IIIa inhibitors is that most of them can potentially induce the receptor to undergo a major conformational change that either exposes neoepitopes for platelet clearance or trigger high-affinity state when the drug dissociates from the receptor, facilitating instead of inhibiting its binding to ligand. ${ }^{150}$ This could cause the paradoxical increase in mortality on treatment for MI patients. As an alternative, a small-molecule GPIIb/ IIIa antagonist, known as RUC-4, binds to the metal ionbinding site on the GPIIb/IIIa. It inhibits ligand binding but does not induce GPIIb/IIIa conformational change or activation (figure 2A). Furthermore, in preclinical studies, RUC-4 showed potent antithrombotic efficacy (table 1) ${ }^{150}$ An interesting aspect of RUC-4 is its suitability for intramuscular injection, which raises the prospect of administration in prehospital emergency settings. ${ }^{150}$ However, the bleeding risk profile of this agent remains to be evaluated.

\section{GPVI: a potential mechanosensor and antithrombotic target}

Aside from GPIb and GPIIb/IIIa, many other receptors on platelet surface may also mediate platelet mechanosensing. One topical candidate is GPVI, which is exclusively expressed on platelets and megakaryocytes. It is associated with the Fc receptor $\gamma$-chain, which contains an immunoreceptor tyrosine-based activation motif (ITAM). Its engagement with ligands, such as collagen, leads to ITAM-dependent signaling and potent platelet activation. ${ }^{81}$ GPVI plays an important role in haemostasis and thrombosis, not only via its own binding to collagen but also through the triggering of GPIIb/IIIa and integrin $\alpha_{2} \beta_{1}$ activation. ${ }^{151}$ In this context, GPVI was suggested to play a mechanosensing role. ${ }^{152}$ However, direct evidence and the detailed mechanosensing mechanism are yet to be revealed. Recently, fibrin was identified as a new GPVI ligand. ${ }^{153} 154$ GPVI-fibrin interaction seems to stabilize thrombus formation under both low-shear and highshear conditions. ${ }^{153}$ Moreover, GPVI was suggested to co-associate with GPIb $\alpha$ to coordinate thrombotic output across these haemodynamic conditions. ${ }^{155}$ Intriguingly, patients and mice with GPVI deficiency only display a mild bleeding diathesis, ${ }^{155}$ whereas mice lacking GPVI are protected against arterial thrombosis and subsequent neointima formation ${ }^{156}$ and demonstrate an impaired thrombus formation under high-shear conditions. ${ }^{157}$

Platelet GPVI has been gradually recognized to play a role in ischaemic stroke. ${ }^{158-160}$ Platelet adhesion and activation enhance the infarct growth by promoting an inflammatory response. ${ }^{77}$ GPVI-mediated platelet activation can lead to the release of IL- $1 \alpha$ that induces cerebrovascular inflammation. ${ }^{161}$ Thus, GPVI may serve as an antithromboinflammation target. ${ }^{162}$ Currently, two strategies targeting GPVI have reached advanced stages of development. The first is the antibody Fab 9O12, which binds and blocks the collagen/fibrin-binding site of GPVI with high affinity ${ }^{153} 163$ (figure 1). This approach has demonstrable antithrombotic efficacy in preclinical models of thrombosis and seems to maintain haemostasis (table 1). A humanized $\mathrm{scFv}$ form of 9012 is being prepared to enter early phase clinical trial. ${ }^{164}$ The second anti-GPVI is the humanized Fc fusion protein of the GPVI ectodomain called revacept ${ }^{165}$ (figure 1). In animal models, revacept protected against thrombosis, ischaemia-reperfusion injury ${ }^{166}$ and stroke. ${ }^{167}$ In phase I clinical trials, revacept inhibited collagen-induced human platelet aggregation. ${ }^{165}$ Phase II trials of revacept in patients with carotid artery stenosis, transient ischaemic attack, or stroke are ongoing (table 1). Interestingly, this therapeutic seems to be particularly potent at inhibiting thrombus growth under pathological shear conditions ex vivo, suggesting that its antithrombotic effects might be maintained at sites of atherosclerotic plaque rupture, ${ }^{168}$ consistent with the fact that collagens are highly abundant in atherosclerotic plaques. Some other GPVI targeted agents that are under investigation, such as losartan, ${ }^{169}$ have been shown to inhibit the binding of GPVI to collagen (table 1; figure 1).

\section{CONCLUDING REMARKS}

Many FDA approved antiplatelet agents are less efficient in relieving arterial thrombosis in severe stenosis, ${ }^{170}$ in part due to that they only target agonist pathways rather than the biomechanical platelet aggregation mechanisms. Hereby, we propose that targeting platelet mechanosensing pathways may represent a novel strategy to prevent thrombotic complications. This new strategy uses high-shear flow as the 'trigger' of effect, and therefore should be specific in preventing occlusive thrombosis in stenosed arteries. In parallel, current inhibitors of GPIb and GPIIb/IIIa extracellular activity were shown to cause adverse effect of bleeding, because they are unable to discriminate the haemostatic versus thrombotic conditions. ${ }^{171} 172$ From a biomechanical perspective, we highlight that although thrombosis and haemostasis share similarity in most aspects, a key difference is that only thrombosis heavily relies on shear-resistant platelet aggregation for endovascular clot growth. This comparison is supported by an interesting evolutionary perspective: the avian thrombocytes have similar adhesion and signaling behaviours as mammalian platelets, but cannot form shear-resistant aggregates ${ }^{173}$; in consequence, thrombocytes support haemostasis but cannot form occlusive thrombi in vivo. Therefore, inhibitors that weaken GPIb and GPIIb/IIIa binding under thrombotic haemodynamic conditions, should selectively prevent shear-resistant platelet aggregates towards artery occlusion. The above new antithrombotic strategies, which are under development or yet to be tested, promise a 'mechano-medicine' to solve the long lingering question 
of how to effectively inhibit arterial thrombosis without causing excessive bleeding.

Correction notice This article has been corrected since it was first published. Orcid iD forauthor Lining Arnold Ju has been added.

Contributors Both authors wrote the manuscript and made the table. YC drew the figures.

Funding This work was supported by grants from Sydney Research Accelerator (SOAR) prize (L.A.J.), The Royal College of Pathologists of Australasia Kanematsu research award (L.A.J.) and the Cardiac Society of Australia and New Zealand BAYER Young Investigator Research Grant (L.A.J.). We thank Zaverio Ruggeri, Yilong Wang, Liping Liu, Jing-fei Dong and Yi Qian for helpful discussion. Y.C. is a MERU (Medolago-Ruggeri) Foundation post-doctoral awardee. L.A.J. is an Australian Research Council DECRA fellow (DE190100609) and a National Heart Foundation Future Leader fellow (102532)

Competing interests None declared.

Patient consent for publication Not required.

Provenance and peer review Commissioned; internally peer reviewed.

Open access This is an open access article distributed in accordance with the Creative Commons Attribution Non Commercial (CC BY-NC 4.0) license, which permits others to distribute, remix, adapt, build upon this work non-commercially, and license their derivative works on different terms, provided the original work is properly cited, appropriate credit is given, any changes made indicated, and the use is non-commercial. See: http://creativecommons.org/licenses/by-nc/4.0/.

ORCID iDs

Yunfeng Chen http://orcid.org/0000-0001-7618-107X

Lining Arnold Ju http://orcid.org/0000-0002-7591-0864

\section{REFERENCES}

1 Jackson SP. Arterial thrombosis--insidious, unpredictable and deadly. Nat Med 2011;17:1423-36.

2 Benjamin EJ, Virani SS, Callaway CW, et al. Heart disease and stroke Statistics-2018 update: a report from the American heart association. Circulation 2018;137:e67-492.

3 Angiolillo DJ, Bernardo E, Sabaté M, et al. Impact of platelet reactivity on cardiovascular outcomes in patients with type 2 diabetes mellitus and coronary artery disease. J Am Coll Cardiol 2007:50:1541-7.

4 McFadyen JD, Schaff M, Peter K. Current and future antiplatelet therapies: emphasis on preserving haemostasis. Nat Rev Cardiol 2018;15:181-91.

5 Nesbitt WS, Westein E, Tovar-Lopez FJ, et al. A shear gradientdependent platelet aggregation mechanism drives thrombus formation. Nat Med 2009;15:665-73.

6 Chen Y, Ju L, Rushdi M, et al. Receptor-Mediated cell mechanosensing. Mol Biol Cell 2017;28:3134-55.

7 Hansen CE, Qiu Y, McCarty OJT, et al. Platelet mechanotransduction. Annu Rev Biomed Eng 2018;20:253-75.

8 Mazzucato M, Pradella P, Cozzi MR, et al. Sequential cytoplasmic calcium signals in a 2-stage platelet activation process induced by the glycoprotein Ibalpha mechanoreceptor. Blood 2002;100:2793-800.

9 Nesbitt WS, Kulkarni S, Giuliano S, et al. Distinct Glycoprotein $\mathrm{lb} / \mathrm{V} / \mathrm{IX}$ and Integrin $\alpha_{\text {Ib }} \beta_{3}$-dependent Calcium Signals Cooperatively Regulate Platelet Adhesion under Flow. J Biol Chem 2002;277:2965-72

10 Kasirer-Friede A, Cozzi MR, Mazzucato M, et al. Signaling through GP Ib-IX-V activates $\alpha$ llb $\beta 3$ independently of other receptors. Blood 2004;103:3403-11.

11 Qiu Y, Brown AC, Myers DR, et al. Platelet mechanosensing of substrate stiffness during clot formation mediates adhesion, spreading, and activation. Proc Natl Acad Sci U S A 2014;111:14430-5.

12 Chen Y, Ju LA, Zhou F, et al. An integrin $\alpha$ llb 33 intermediate affinity state mediates biomechanical platelet aggregation. Nat Mater 2019;18:760-9.

13 Savage B, Almus-Jacobs F, Ruggeri ZM. Specific synergy of multiple Substrate-Receptor interactions in platelet thrombus formation under flow. Cell 1998;94:657-66.

14 Furlan M. Von Willebrand factor: molecular size and functional activity. Ann Hematol 1996;72:341-8.
15 Ikeda Y, Handa M, Kawano K, et al. The role of von Willebrand factor and fibrinogen in platelet aggregation under varying shear stress. J Clin Invest 1991;87:1234-40

16 Springer TA. Biology and physics of von Willebrand factor concatamers. J Thromb Haemost 2011;9:130-43.

17 Farrell DH, Thiagarajan P, Chung DW, et al. Role of fibrinogen alpha and gamma chain sites in platelet aggregation. Proc Natl Acad Sci U S A 1992;89:10729-32.

18 Peter K, Schwarz M, Ylänne J, et al. Induction of fibrinogen binding and platelet aggregation as a potential intrinsic property of various glycoprotein Ilb/llla (alphallbbeta3) inhibitors. Blood 1998:92:3240-9.

19 Rooney MM, Farrell DH, van Hemel BM, et al. The contribution of the three hypothesized integrin-binding sites in fibrinogen to platelet-mediated clot retraction. Blood 1998;92:2374-81.

$20 \mathrm{Ni} \mathrm{H}$, Yuen PST, Papalia JM, et al. Plasma fibronectin promotes thrombus growth and stability in injured arterioles. Proc Natl Acad Sci U S A 2003;100:2415-9.

21 Wang Y, Reheman A, Spring CM, et al. Plasma fibronectin supports hemostasis and regulates thrombosis. J Clin Invest 2014;124:4281-93.

22 Cho J, Mosher DF. Impact of fibronectin assembly on platelet thrombus formation in response to type I collagen and von Willebrand factor. Blood 2006;108:2229-36.

23 Savage B, Saldívar E, Ruggeri ZM. Initiation of platelet adhesion by arrest onto fibrinogen or translocation on von Willebrand factor. Cell 1996;84:289-97.

24 Ruggeri ZM. Platelet adhesion under flow. Microcirculation 2009;16:58-83.

25 Goto S, Ikeda Y, Saldívar E, et al. Distinct mechanisms of platelet aggregation as a consequence of different shearing flow conditions. J Clin Invest 1998;101:479-86.

26 Ruggeri ZM, Orje JN, Habermann R, et al. Activation-Independent platelet adhesion and aggregation under elevated shear stress. Blood 2006;108:1903-10.

27 Sakurai Y, Fitch-Tewfik JL, Qiu Y, et al. Platelet geometry sensing spatially regulates $\alpha$-granule secretion to enable matrix selfdeposition. Blood 2015;126:531-8.

28 McCarty OJT, Calaminus SDJ, Berndt MC, et al. von Willebrand factor mediates platelet spreading through glycoprotein $\mathrm{Ib}$ and alpha(llb)beta3 in the presence of botrocetin and ristocetin, respectively. J Thromb Haemost 2006;4:1367-78.

29 Merten M. \& Thiagarajan, P. P-selectin expression on platelets determines size and stability of platelet aggregates. Circulation 2000;102:1931-6.

30 Zhang D, Gao Z-G, Zhang K, et al. Two disparate ligand-binding sites in the human P2Y1 receptor. Nature 2015;520:317-21.

31 Hollopeter $\mathrm{G}$, Jantzen $\mathrm{H}-\mathrm{M}$, Vincent $\mathrm{D}$, et al. Identification of the platelet ADP receptor targeted by antithrombotic drugs. Nature 2001;409:202-7.

32 Offermanns S. Activation of platelet function through G ProteinCoupled receptors. Circ Res 2006;99:1293-304.

33 Coughlin SR. How the protease thrombin talks to cells. Proc Natl Acad Sci U S A 1999;96:11023-7.

34 Kaplan ZS, Jackson SP. The role of platelets in atherothrombosis. Hematology 2011;2011:51-61.

35 Bennett JS, Vilaire G. Exposure of platelet fibrinogen receptors by ADP and epinephrine. J Clin Invest 1979;64:1393-401.

36 Damman P, Woudstra P, Kuijt WJ, et al. P2Y12 platelet inhibition in clinical practice. J Thromb Thrombolysis 2012;33:143-53.

37 Smith JB, Araki H, Lefer AM. Thromboxane A2, prostacyclin and aspirin: effects on vascular tone and platelet aggregation. Circulation 1980;62:V19-25.

38 Ageno W, Gallus AS, Wittkowsky A, et al. Oral anticoagulant therapy: antithrombotic therapy and prevention of thrombosis, 9th ED: American College of chest physicians evidence-based clinical practice guidelines. Chest 2012;141:e44S-88.

39 Chesebro JH, Badimon JJ, Hassinger NL, et al. Acute myocardial infarction and the role of aspirin, heparin, and warfarin. $J$ Thromb Thrombolysis 1995;1:231-5.

40 Zhang XF, Cheng X. Platelet mechanosensing axis revealed. Nat Mater 2019;18:661-2.

41 Springer TA, factor vonW. Jedi knight of the bloodstream. Blood 2014;124:1412-25.

42 Ulrichts $\mathrm{H}$, Udvardy M, Lenting PJ, et al. Shielding of the A1 domain by the D'D3 domains of von Willebrand factor modulates its interaction with platelet glycoprotein Ib-IX-V. J Biol Chem 2006;281:4699-707.

43 Aponte-Santamaría C, Huck V, Posch S, et al. Force-sensitive autoinhibition of the von Willebrand factor is mediated by interdomain interactions. Biophys J 2015;108:2312-21. 
44 Martin C, Morales LD, Cruz MA. Purified A2 domain of von Willebrand factor binds to the active conformation of von Willebrand factor and blocks the interaction with platelet glycoprotein Ibalpha. $J$ Thromb Haemost 2007:5:1363-70.

45 Sing CE, Alexander-Katz A. Elongational Flow Induces the Unfolding of von Willebrand Factor at Physiological Flow Rates. Biophys J 2010;98:L35-7.

$46 \mathrm{Fu} \mathrm{H}$, Jiang Y, Yang D, et al. Flow-Induced elongation of von Willebrand factor precedes tension-dependent activation. Nat Commun 2017;8:324.

47 Barg A, Ossig R, Goerge T, et al. Soluble plasma-derived von Willebrand factor assembles to a haemostatically active filamentous network. Thromb Haemost 2007;97:514-26.

48 Schneider SW, Nuschele S, Wixforth A, et al. Shear-Induced unfolding triggers adhesion of von Willebrand factor fibers. Proc Natl Acad Sci U S A 2007;104:7899-903.

49 Löf A, Müller JP, Brehm MA. A biophysical view on von Willebrand factor activation. J Cell Physiol 2018;233:799-810.

50 Savage B, Sixma JJ, Ruggeri ZM. Functional self-association of von Willebrand factor during platelet adhesion under flow. Proc Natl Acad Sci U S A 2002;99:425-30.

51 Dayananda KM, Singh I, Mondal N, et al. Von Willebrand factor self-association on platelet Gplb $\alpha$ under hydrodynamic shear: effect on shear-induced platelet activation. Blood 2010;116:3990-8.

52 Butera D, Passam F, Ju L, et al. Autoregulation of von Willebrand factor function by a disulfide bond switch. Sci Adv 2018;4:eaaq1477.

53 Murphy DA, Hockings LE, Andrews RK, et al. Extracorporea membrane Oxygenation-Hemostatic complications. Transfus Med Rev 2015;29:90-101.

54 Doggett TA, Girdhar G, Lawshé A, et al. Selectin-Like kinetics and biomechanics promote rapid platelet adhesion in flow: the GPIb $\alpha$ vWF tether bond. Biophys J 2002;83:194-205.

55 Yago T, Lou J, Wu T, et al. Platelet glycoprotein Ibalpha forms catch bonds with human WT vWF but not with type 2B von Willebrand disease vWF. J Clin Invest 2008;118:3195-207.

56 Doggett TA, Girdhar G, Lawshe A, et al. Alterations in the intrinsic properties of the GPIb $\alpha-$ VWF tether bond define the kinetics of the platelet-type von Willebrand disease mutation, Gly233Val. Blood 2003:102:152-60.

57 Ju L, Dong J-fei, Cruz MA, et al. The N-terminal flanking region of the A1 domain regulates the force-dependent binding of von Willebrand factor to platelet glycoprotein Ibo. J Biol Chem 2013;288:32289-301.

58 Ju L, Lou J, Chen Y, et al. Force-Induced unfolding of leucine-rich repeats of glycoprotein Ib $\alpha$ strengthens ligand interaction. Biophys J 2015;109:1781-4.

59 Le Behot A, Gauberti M, Martinez De Lizarrondo S, et al. Gplb $\alpha$ VWF blockade restores vessel patency by dissolving platelet aggregates formed under very high shear rate in mice. Blood 2014;123:3354-63.

60 Ju L, Chen Y, Xue L, et al. Cooperative unfolding of distinctive mechanoreceptor domains transduces force into signals. eLife 2016;5:e15447.

61 Yap CL, Hughan SC, Cranmer SL, et al. Synergistic adhesive interactions and signaling mechanisms operating between platelet glycoprotein Ib/IX and integrin alpha Ilbbeta 3. Studies in human platelets ANS transfected Chinese hamster ovary cells. J Biol Chem 2000;275:41377-88.

62 Nesbitt WS, Giuliano S, Kulkarni S, et al. Intercellular calcium communication regulates platelet aggregation and thrombus growth. J Cell Biol 2003;160:1151-61.

63 Ju L, Chen Y, Li K, et al. Dual biomembrane force probe enables single-cell mechanical analysis of signal crosstalk between multiple molecular species. Sci Rep 2017;7:14185.

64 Gu M, Xi X, Englund GD, et al. Analysis of the Roles of 14- - $_{3}$ in the Platelet Glycoprotein Ib-IX-Mediated Activation of Integrin $\alpha_{1 \mathrm{~b}} \beta_{3}$ Using a Reconstituted Mammalian Cell Expression Model. J Cell Biol 1999;147:1085-96.

65 Feng S, Reséndiz JC, Lu X, et al. Filamin a binding to the cytoplasmic tail of glycoprotein Ib $\alpha$ regulates von Willebrand factorinduced platelet activation. Blood 2003;102:2122-9.

66 Yin H, Liu J, Li Z, et al. Src family tyrosine kinase Lyn mediates VWF/GPIb-IX-induced platelet activation via the cGMP signaling pathway. Blood 2008;112:1139-46.

67 Estevez B, Du X. New concepts and mechanisms of platelet activation signaling. Physiology 2017;32:162-77.

68 Clemetson J, Clemetson K. Platelet GPIb complex as a target for anti-thrombotic drug development. Thromb Haemost 2008:99:473-9.
69 Chen J, Tan K, Zhou H, et al. Modifying murine von Willebrand factor A1 domain for in vivo assessment of human platelet therapies. Nat Biotechnol 2008;26:114-9.

70 Chen J, Zhou H, Diacovo A, et al. Exploiting the kinetic interplay between GPIb $\alpha-V W F$ binding interfaces to regulate hemostasis and thrombosis. Blood 2014;124:3799-807.

71 Ulrichts H, Silence K, Schoolmeester A, et al. Antithrombotic drug candidate ALX-0081 shows superior preclinical efficacy and safety compared with currently marketed antiplatelet drugs. Blood 2011;118:757-65.

72 Momi S, Tantucci M, Van Roy M, et al. Reperfusion of cerebral artery thrombosis by the GPlb-VWF blockade with the nanobody $A L X-0081$ reduces brain infarct size in guinea pigs. Blood 2013;121:5088-97.

73 Kanaji S, Orje JN, Kanaji T, et al. Humanized GPIbo-von Willebrand factor interaction in the mouse. Blood Adv 2018;2:2522-32.

74 Wadanoli M, Sako D, Shaw G, et al. The von Willebrand factor antagonist (GPG-290) prevents coronary thrombosis without prolongation of bleeding time. Thromb Haemost 2007;98:397-405.

75 Bae O-N. Targeting von Willebrand factor as a novel anti-platelet therapy; application of ARC1779, an anti-vWF aptamer, against thrombotic risk. Arch Pharm Res 2012;35:1693-9.

76 Cauwenberghs N, Meiring M, Vauterin S, et al. Antithrombotic effect of platelet glycoprotein Ib-blocking monoclonal antibody Fab fragments in nonhuman primates. Arterioscler Thromb Vasc Biol 2000;20:1347-53.

77 Kleinschnitz Cet al. Targeting platelets in acute experimental stroke: impact of glycoprotein lb, VI, and Ilb/IIla blockade on infarct size, functional outcome, and intracranial bleeding. Circulation 2007;115:2323-30.

78 Yeh $\mathrm{C}-\mathrm{H}$, Chang $\mathrm{M}-\mathrm{C}$, Peng $\mathrm{H}-\mathrm{C}$, et al. Pharmacological characterization and antithrombotic effect of agkistin, a platelet glycoprotein Ib antagonist. Br J Pharmacol 2001;132:843-50.

79 Lei X, Reheman A, Hou Y, et al. Anfibatide, a novel GPIb complex antagonist, inhibits platelet adhesion and thrombus formation in vitro and in vivo in murine models of thrombosis. Thromb Haemost 2014;111:279-89

80 Stoll G, Kleinschnitz C, Nieswandt B. Molecular mechanisms of thrombus formation in ischemic stroke: novel insights and targets for treatment. Blood 2008;112:3555-62.

$81 \mathrm{Xu}$ XR, Carrim N, Neves MAD, et al. Platelets and platelet adhesion molecules: novel mechanisms of thrombosis and anti-thrombotic therapies. Thromb J 2016;14:29.

$82 \mathrm{Li} \mathrm{T-T,} \mathrm{Fan} \mathrm{M-L,} \mathrm{Hou} \mathrm{S-X,} \mathrm{et} \mathrm{al.} \mathrm{A} \mathrm{novel} \mathrm{snake} \mathrm{venom-derived} \mathrm{GPIb}$ antagonist, anfibatide, protects mice from acute experimental ischaemic stroke and reperfusion injury. $\mathrm{Br} \mathrm{J}$ Pharmacol 2015;172:3904-16.

83 Zheng L, Mao Y, Abdelgawwad MS, et al. Therapeutic efficacy of the platelet glycoprotein lb antagonist anfibatide in murine models of thrombotic thrombocytopenic purpura. Blood Advances 2016;1:75-83.

84 Sinha G. Ablynx drops lead nanobody. Nat Biotechnol 2012;30:124

85 Markus HS, McCollum C, Imray C, et al. The von Willebrand inhibitor ARC1779 reduces cerebral embolization after carotid endarterectomy. Stroke 2011;42:2149-53.

86 Duggan S. Caplacizumab: first global approval. Drugs 2018;78:1639-42.

87 Scully M, Cataland SR, Peyvandi F, et al. Caplacizumab treatment for acquired thrombotic thrombocytopenic purpura. N Engl J Med 2019;380:335-46

88 Donadelli R, Orje JN, Capoferri C, et al. Size regulation of von Willebrand factor-mediated platelet thrombi by ADAMTS13 in flowing blood. Blood 2006;107:1943-50.

89 Shida Y, Swystun LL, Brown C, et al. Shear stress and plateletinduced tensile forces regulate ADAMTS13-localization within the platelet thrombus. Res Pract Thromb Haemost 2019;3:254-60.

90 Chen X, Cheng X, Zhang S, et al. Adamts13: an emerging target in stroke therapy. Front Neurol 2019;10:772.

91 Zhao B-Q, Chauhan AK, Canault M, et al. Von Willebrand factorcleaving protease ADAMTS13 reduces ischemic brain injury in experimental stroke. Blood 2009;114:3329-34

92 Yin H, Stojanovic-Terpo A, Xu W, et al. Role for platelet glycoprotein $\mathrm{Ib}-\mathrm{IX}$ and effects of its inhibition in endotoxemia-induced thrombosis, thrombocytopenia, and mortality. Arterioscler Thromb Vasc Biol 2013;33:2529-37.

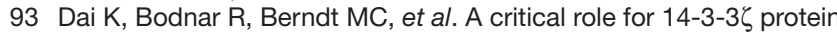
in regulating the VWF binding function of platelet glycoprotein Ib-IX and its therapeutic implications. Blood 2005;106:1975-81.

94 Labrijn AF, Janmaat ML, Reichert JM, et al. Bispecific antibodies: a mechanistic review of the pipeline. Nat Rev Drug Discov 2019;18:585-608. 
95 Takagi J, Petre BM, Walz T, et al. Global conformational rearrangements in integrin extracellular domains in outside-in and inside-out signaling. Cell 2002;110:599-611.

96 Ye F, Hu G, Taylor D, et al. Recreation of the terminal events in physiological integrin activation. J Cell Biol 2010;188:157-73.

97 Ye F, Kim C, Ginsberg MH. Reconstruction of integrin activation. Blood 2012;119:26-33.

98 Xiao T, Takagi J, Coller BS, et al. Structural basis for allostery in integrins and binding to fibrinogen-mimetic therapeutics. Nature 2004;432:59-67.

99 Peterson JA, Nelson TN, Kanack AJ, et al. Fine specificity of drugdependent antibodies reactive with a restricted domain of platelet GPIlla. Blood 2008;111:1234-9.

100 Mitchell WB, Li J, Murcia M, et al. Mapping early conformational changes in alphallb and beta3 during biogenesis reveals a potential mechanism for alphallbbeta3 adopting its bent conformation. Blood 2007:109:3725-32.

101 Litvinov RI, Barsegov V, Schissler AJ, et al. Dissociation of bimolecular $\alpha$ llbß3-fibrinogen complex under a constant tensile force. Biophys J 2011;100:165-73.

102 Litvinov RI, Mekler A, Shuman H, et al. Resolving two-dimensional kinetics of the integrin $\alpha$ llb $\beta 3$-fibrinogen interactions using binding-unbinding correlation spectroscopy. J Biol Chem 2012;287:35275-85.

103 Litvinov RI, Farrell DH, Weisel JW, et al. The platelet integrin $\alpha$ llb $\beta 3$ differentially interacts with fibrin versus fibrinogen. $\mathrm{J} \mathrm{Biol} \mathrm{Chem}$ 2016;291:7858-67.

104 Shen B, Zhao X, O'Brien KA, et al. A directional switch of integrin signalling and a new anti-thrombotic strategy. Nature 2013;503:131-5.

105 Hynes RO. Integrins: bidirectional, allosteric signaling machines. Cell 2002;110:673-87.

106 Yang J, Zhu L, Zhang H, et al. Conformational activation of talin by RIAM triggers integrin-mediated cell adhesion. Nat Commun 2014;5:5880.

107 Schürpf T, Springer TA. Regulation of integrin affinity on cell surfaces. Embo J 2011;30:4712-27.

108 Luo B-H, Carman CV, Springer TA. Structural basis of integrin regulation and signaling. Annu Rev Immunol 2007;25:619-47.

109 Xie C, Zhu J, Chen X, et al. Structure of an integrin with an alphal domain, complement receptor type 4. Embo J 2010;29:666-79.

110 Nishida N, Xie C, Shimaoka M, et al. Activation of leukocyte beta2 integrins by conversion from bent to extended conformations. Immunity 2006;25:583-94.

111 Takagi J, Strokovich K, Springer TA, et al. Structure of integrin alpha5beta1 in complex with fibronectin. Embo $J$ 2003;22:4607-15.

$112 \mathrm{Li}$ J, Springer TA. Energy landscape differences among integrins establish the framework for understanding activation. J Cell Biol 2018;217:397-412.

113 Zhu J, Zhu J, Springer TA. Complete integrin headpiece opening in eight steps. J Cell Biol 2013;201:1053-68.

114 Bledzka K, Smyth SS, Plow EF. Integrin $\alpha$ llbß33: from discovery to efficacious therapeutic target. Circ Res 2013;112:1189-200.

115 Hodivala-Dilke KM, McHugh KP, Tsakiris DA, et al. Beta3-integrindeficient mice are a model for Glanzmann thrombasthenia showing placental defects and reduced survival. J Clin Invest 1999;103:229-38

$116 \mathrm{Ni} \mathrm{H}$, Denis CV, Subbarao S, et al. Persistence of platelet thrombus formation in arterioles of mice lacking both von Willebrand factor and fibrinogen. J Clin Invest 2000;106:385-92.

117 Ley K, Rivera-Nieves J, Sandborn WJ, et al. Integrin-Based therapeutics: biological basis, clinical use and new drugs. Nat Rev Drug Discov 2016;15:173-83.

118 Li A, Guo Q, Kim C, et al. Integrin $\alpha$ ll B tail distal of GFFKR participates in inside-out $\alpha$ ll B $\beta 3$ activation. J Thromb Haemost 2014:12:1145-55

119 Feral CC, Nishiya N, Fenczik CA, et al. Cd98Hc (SLC3A2) mediates integrin signaling. Proc Natl Acad Sci U S A 2005;102:355-60.

120 Sharda A, Furie B. Regulatory role of thiol isomerases in thrombus formation. Expert Rev Hematol 2018;11:437-48.

121 Passam FH, Lin L, Gopal S, et al. Both platelet- and endothelial cellderived ERp5 support thrombus formation in a laser-induced mouse model of thrombosis. Blood 2015;125:2276-85

122 Jasuja R, Passam FH, Kennedy DR, et al. Protein disulfide isomerase inhibitors constitute a new class of antithrombotic agents. J Clin Invest 2012;122:2104-13.

123 Cho J, Furie BC, Coughlin SR, et al. A critical role for extracellular protein disulfide isomerase during thrombus formation in mice. $J$ Clin Invest 2008;118:1123-31.
124 Cho J, Kennedy DR, Lin L, et al. Protein disulfide isomerase capture during thrombus formation in vivo depends on the presence of $\beta 3$ integrins. Blood 2012;120:647-55

125 Passam F, Chiu J, Ju L, et al. Mechano-redox control of integrin de-adhesion. Elife 2018;7. doi:10.7554/eLife.34843. [Epub ahead of print: 2206 2018].

126 Wang L, Wu Y, Zhou J, et al. Platelet-Derived ERp57 mediates platelet incorporation into a growing thrombus by regulation of the

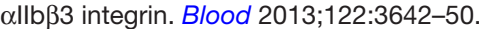

127 Holbrook L-M, Sasikumar P, Stanley RG, et al. The platelet-surface thiol isomerase enzyme ERp57 modulates platelet function. $J$ Thromb Haemost 2012;10:278-88.

128 Zhu G, Zhang Q, Reddy EC, et al. The integrin PSI domain has an endogenous thiol isomerase function and is a novel target for antiplatelet therapy. Blood 2017:129:1840-54.

129 Jordan PA, Stevens JM, Hubbard GP, et al. A role for the thiol isomerase protein ERP5 in platelet function. Blood 2005; 105:1500-7

130 Huang J, Li X, Shi X, et al. Platelet integrin $\alpha$ llb $\beta 3$ : signal transduction, regulation, and its therapeutic targeting. $\mathrm{J} \mathrm{Hematol}$ Oncol 2019;12.

131 Kam PCA, Egan MK. Platelet glycoprotein Ilb/Illa antagonists: pharmacology and clinical developments. Anesthesiology 2002;96:1237-49.

132 Derex L, Paris C, Nighoghossian N. Combining intravenous thrombolysis and antithrombotic agents in stroke: an update. J Am Heart Assoc 2018;7. doi:10.1161/JAHA.117.007454. [Epub ahead of print: 13012018$]$

133 Kastrati A, Mehilli J, Neumann F-J, et al. Abciximab in patients with acute coronary syndromes undergoing percutaneous coronary intervention after clopidogrel pretreatment: the ISAR-REACT 2 randomized trial. JAMA 2006;295:1531-8

134 Bosch X, Marrugat J, Sanchis J. Platelet glycoprotein Illb/llla blockers during percutaneous coronary intervention and as the initial medical treatment of non-ST segment elevation acute coronary syndromes. The Cochrane database of systematic reviews 2013:CD002130.

135 Powers WJ, Rabinstein AA, Ackerson T, et al. Guidelines for the early management of patients with acute ischemic stroke: 2019 update to the 2018 guidelines for the early management of acute ischemic stroke: a guideline for healthcare professionals from the American heart Association/American stroke association. Stroke 2019.

136 Wang Y, Gao H, Shi C, et al. Leukocyte integrin Mac-1 regulates thrombosis via interaction with platelet GPIb $\alpha$. Nat Commun 2017;8:15559.

137 Xu XR, Wang Y, Adili R, et al. Apolipoprotein A-IV binds $\alpha$ llb $\beta 3$ integrin and inhibits thrombosis. Nat Commun 2018;9:3608.

138 Jackson SP, Schoenwaelder SM, Goncalves I, et al. Pi 3-kinase p110beta: a new target for antithrombotic therapy. Nat Med 2005;11:507-14.

139 Ju L, McFadyen JD, Al-Daher S, et al. Compression force sensing regulates integrin $\alpha$ llb $\beta 3$ adhesive function on diabetic platelets. Nat Commun 2018;9:1087.

140 Khodier Cet al. Identification of ML359 as a Small Molecule Inhibitor of Protein Disulfide Isomerase. Probe Reports from the NIH Molecular Libraries Program, 2010.

141 Zwicker JI, Schlechter BL, Stopa JD, et al. Targeting protein disulfide isomerase with the flavonoid isoquercetin to improve hypercoagulability in advanced cancer. JCl Insight 2019;4. doi:10.1172/jci.insight.125851. [Epub ahead of print: 2102 2019].

142 Chien C-Y, Hung Y-J, Shieh Y-S, et al. A novel potential biomarker for metabolic syndrome in Chinese adults: circulating protein disulfide isomerase family $\mathrm{A}$, member 4 . PLoS One 2017;12:e0179963.

143 Raturi A, Miersch S, Hudson JW, et al. Platelet microparticleassociated protein disulfide isomerase promotes platelet aggregation and inactivates insulin. Biochim Biophys Acta 2008;1778:2790-6

144 Rosetti F, Chen Y, Sen M, et al. A Lupus-associated Mac-1 variant has defects in integrin allostery and interaction with ligands under force. Cell Rep 2015;10:1655-64.

145 Schwarz M, Meade G, Stoll P, et al. Conformation-Specific blockade of the integrin GPIIb/IIla: a novel antiplatelet strategy that selectively targets activated platelets. Circ Res 2006;99:25-33.

146 Armstrong PC, Peter K. Gpiib/liia inhibitors: from bench to bedside and back to bench again. Thromb Haemost 2012;107:808-14

147 Hohmann JD, Wang X, Krajewski S, et al. Delayed targeting of CD39 to activated platelet GPIIb/llla via a single-chain antibody: breaking the link between antithrombotic potency and bleeding? Blood 2013;121:3067-75. 
148 Stoll P, Bassler N, Hagemeyer CE, et al. Targeting ligand-induced binding sites on GPIIb/Illa via single-chain antibody allows effective anticoagulation without bleeding time prolongation. Arterioscler Thromb Vasc Biol 2007;27:1206-12.

149 Wang X, Palasubramaniam J, Gkanatsas Y, et al. Towards effective and safe thrombolysis and thromboprophylaxis: preclinical testing of a novel antibody-targeted recombinant plasminogen activator directed against activated platelets. Circ Res 2014;114:1083-93.

150 Li J, Vootukuri S, Shang Y, et al. RUC-4: a novel $\alpha$ llb $\beta 3$ antagonist for prehospital therapy of myocardial infarction. Arterioscler Thromb Vasc Biol 2014;34:2321-9.

151 Lecut C, Schoolmeester A, Kuijpers MJE, et al. Principal role of glycoprotein $\mathrm{VI}$ in alpha2beta1 and alphallbbeta3 activation during collagen-induced thrombus formation. Arterioscler Thromb Vasc Biol 2004;24:1727-33.

152 Kee MF, Myers DR, Sakurai Y, et al. Platelet mechanosensing of collagen matrices. PLoS One 2015;10:e0126624.

153 Mammadova-Bach E, Ollivier V, Loyau S, et al. Platelet glycoprotein $\mathrm{VI}$ binds to polymerized fibrin and promotes thrombin generation. Blood 2015;126:683-91.

154 Alshehri OM, Hughes CE, Montague S, et al. Fibrin activates GPVI in human and mouse platelets. Blood 2015;126:1601-8.

155 Gardiner EE. Proteolytic processing of platelet receptors. Res Pract Thromb Haemost 2018;2:240-50.

156 Konishi H, Katoh Y, Takaya N, et al. Platelets activated by collagen through immunoreceptor tyrosine-based activation motif play pivotal role in initiation and generation of neointimal hyperplasia after vascular injury. Circulation 2002;105:912-6.

157 Massberg S, Gawaz M, Grüner S, et al. A crucial role of glycoprotein $\mathrm{VI}$ for platelet recruitment to the injured arterial wall in vivo. $J$ Exp Med 2003;197:41-9.

158 Bigalke B, Stellos K, Geisler T, et al. Expression of platelet glycoprotein $\mathrm{VI}$ is associated with transient ischemic attack and stroke. Eur J Neurol 2010;17:111-7.

159 Induruwa I, Jung SM, Warburton EA. Beyond antiplatelets: the role of glycoprotein VI in ischemic stroke. Int J Stroke 2016;11:618-25.

160 Al-Tamimi M, Gardiner EE, Thom JY, et al. Soluble glycoprotein VI is raised in the plasma of patients with acute ischemic stroke. Stroke 2011;42:498-500.

161 Thornton P, McColl BW, Greenhalgh A, et al. Platelet interleukin-1alpha drives cerebrovascular inflammation. Blood 2010;115:3632-9.
162 Dütting S, Bender M, Nieswandt B. Platelet GPVI: a target for antithrombotic therapy?! Trends Pharmacol Sci 2012;33:583-90.

163 Ohlmann P, Hechler B, Ravanat C, et al. Ex vivo inhibition of thrombus formation by an anti-glycoprotein VI Fab fragment in nonhuman primates without modification of glycoprotein VI expression. J Thromb Haemost 2008;6:1003-11.

164 Muzard J, Bouabdelli M, Zahid M, et al. Design and humanization of a murine ScFv that blocks human platelet glycoprotein $\mathrm{VI}$ in vitro. Febs J 2009;276:4207-22.

165 Ungerer M, Rosport K, Bültmann A, et al. Novel antiplatelet drug revacept (dimeric glycoprotein $\mathrm{VI}-\mathrm{Fc}$ ) specifically and efficiently inhibited collagen-induced platelet aggregation without affecting general hemostasis in humans. Circulation 2011;123:1891-9.

166 Pachel C, Mathes D, Arias-Loza A-P, et al. Inhibition of platelet GPVI protects against myocardial ischemia-reperfusion injury. Arterioscler Thromb Vasc Biol 2016;36:629-35.

167 Goebel S, Li Z, Vogelmann J, et al. The GPVI-Fc fusion protein Revacept improves cerebral infarct volume and functional outcome in stroke. PLoS One 2013;8:e66960.

168 Jamasbi J, Megens RTA, Bianchini M, et al. Differential inhibition of human atherosclerotic Plaque-Induced platelet activation by dimeric GPVI-Fc and Anti-GPVI antibodies: functional and imaging studies. J Am Coll Cardiol 2015;65:2404-15.

169 Jiang P, Loyau S, Tchitchinadze M, et al. Inhibition of glycoprotein $\mathrm{VI}$ clustering by collagen as a mechanism of inhibiting collageninduced platelet responses: the example of losartan. PLoS One 2015;10:e0128744.

170 Braunwald E. Aortic stenosis: then and now. Circulation 2018;137:2099-100.

171 Cranmer SL, Ashworth KJ, Yao Y, et al. High shear-dependent loss of membrane integrity and defective platelet adhesion following disruption of the GPIb $\alpha$-filamin interaction. Blood 2011;117:2718-27.

172 Fan Z, McArdle S, Marki A, et al. Neutrophil recruitment limited by high-affinity bent $\beta 2$ integrin binding ligand in cis. Nat Commun 2016;7:12658.

173 Schmaier AA, Stalker TJ, Runge JJ, et al. Occlusive thrombi arise in mammals but not birds in response to arterial injury: evolutionary insight into human cardiovascular disease. Blood 2011;118:3661-9. 